DOI: $10.4274 /$ tpa. 1816

\title{
Protein losing enteropathy in children
}

\author{
Ondokuz Mayıs University, Medical Faculty, Pediatric Gastroenterology, Division of Hepatology and Nutrition, Samsun, Turkey \\ Gönül Çaltepe, Atakan Comba
}

\section{Summary}

Protein-losing enteropathy is a medical condition which is characterized by loss of protein, vitamin and trace elements into the intestines which can be complicated by various diseases. The main causes of protein-losing enteropathy in children are primary or secondary intestinal lymphangiectesia, Menetrier disease, inflammatory and immunological disorders. Hypoalbuminemia, developed due to intestinal protein loss, provides the basis of clinical findings. Treatment and prognosis of the disease is closely related to the underlying disease. In this paper, the causes of protein-losing enteropapathy, clinical findings and treatment approaches were reviewed in the light of current information. (Turk Arch Ped 2013; 48: 7-12)

Key words: Child, hypoalbuminemia, protein-losing enteropathy

\section{Introduction}

Protein-losing enteropathy (PLE) is a clinical condition which is characterized with excessive protein loss from the gastrointestinal system and involves different diseases in the background. Protein-losing enteropathy may arise from gastrointestinal diseases or non-gastrointestinal diseases (Table 1) $(1,2,3)$. While loss of proteins leads to significant decreases in the plasma levels of the proteins with long half-life including albumin, seruloplasmin and immunoglobulins (IgA, $\operatorname{lgG}$, IgM), no significant change occurs in the plasma levels of the proteins with a short half-life including $\mathrm{lgE}$, coagulation factors, prealbumin and transferrin (2). In protein-losing enteropathy, iron, lipids and trace elements are also lost from the intestines in addition to proteins (4).

Hypoalbuminemia which develops as a result of loss of albumin from the intestines constitutes the basis of the clinical findings. Plasma albumin level depends on the relation between the synthesis, destruction and distribution of albumin in tissues. While hormonal factors and inflammatory processes are effective on albumin synthesis in the body, the main role is played by nutrition; essential amino acids (especially tryptophan) are required for synthesis of albumin (3). Normally, $6-10 \%$ of plasma albumin is reduced daily by being destroyed or lost from the gastrointestinal system. In patients with protein- losing enteropathy, this loss from the gastrointestinal system increases up to $60 \%$. Although the ability of the liver to synthesize albumin is increased to compensate for this, it is not enough. This results in hypoalbuminemia in the patients $(1,3)$.

\section{Pathophysiology}

Protein-losing enteropathy is a clinical condition which develops as a life-threatening complication of some diseases which are not related with each other including primary intestinal lymphangiectasia (PIL), inflammatory bowel diseases, congenital glycolysation disorder and systemic lupus erythematosus (5). PLE may develop in many diseases which cause mucosal inflammation in the gastrointestinal system. The classical examples of these diseases include inflammatory bowel diseases including Crohn's disease and ulcerative colitis. Inflammation which develops in the intestinal mucosa increases mucosal permeability by changing the cellular integrity. Superficial epithelial loss leads to protein loss into the intestinal lumen and protein-rich fluid escapes from the epithelium into the lumen depending on the degree of mucosal damage (1). PLE may develop in the absence of mucosal inflammation in some gastrointestinal diseases. For example, Menetrier disease frequently develops in relation with cytotomegalovirus and helicobacter pylori and is characterized with giant folds in 
the stomach. It is manifested by nonspecific gastrointestinal symptoms including nausea, vomiting, loss of appetite, weight loss and edema. It generally has a good prognosis in children, limits itself and recurrence or permanent damage are not observed. In Menetrier disease, parietal cells and acid release decrease and protein-rich fluid escapes through the wide intercellular "tight junctions" into the stomach. Studies have shown that the "epidermal growth factor" receptors are excessively stimulated by "transforming growth factor $\beta$ ". Therefore, epidermal growth factor receptor antagonists (cetuximab) have been used in some resistant cases and reported to be efficient $(1,3,6)$. In celiac disease, loss of plasma proteins from the intercellular space is enhanced because of loss of superficial epithelium and villus. Intestinal permeability increases in conditions which are accompanied by eosinophilic gastroenteritis and mast cell infiltration including milk and soya protein allergy or eosinophilic gastroenteritis, $(1,7)$. In systemic lupus erithematosus, intravascular complement activation is blamed for development of PLE. Decrease in complement (C)3 and $\mathrm{C} 4$ levels and complement activation and additionally increase in INF $\alpha$, IL 6 and TNF $\alpha$ lead to increase in permeability of the intestinal mucosa (8).

Intestinal lymphangiectasies constitute the other large class of protein-losing enteropathies (Table 1). Primary intestinal lymphangiectasia is a condition defined in 1961 for the first time characterized with local or diffuse enlargement in enteric lymphatics which can be associated with lymphatic anomalies in the other parts of the body (9). Different clinical pictures may arise depending on the localization of the enlarged lymphatics namely the mucosa, submucosa or serosa. Studies have found that VEGFR3 (vascular endothelial growth factor receptor 3), PROX1 (prospero-related homeobox-transcriptional factor), FOXC2 (forkhead transcriptional factor) and SOX18 genes are involved in the development of the lymphatic system. Hokari et al. (10) showed that there were changes in mRNA expression of these genes by duedonum biopsy in patients with primary intestinal lymphangiectasia. Patients with primary intestinal lymphangiectasia are usually diagnosed before the age of three and girls and boys are affected equally. Enlargement and stasis in the lymphatics result in tears in the lymphatic vessels and loss of protein-rich fluid into the gastrointestinal system. This leads to hypoalbuminemia, lymphopenia, hypogammaglobulinemia and loss of the fat soluble vitamins. Clinically, it is manifested by unilateral or bilateral low extremity edema, diarrhea, nausea, vomiting and fatty stools $(11,12)$.

Intestinal lymphangiectasia may occur secondary to stasis in the lymphatics or increase in the lymphatic pressure. While lymphatic stasis occurs in conditions including Crohn disease, sarcoidosis and lymphoma, increase in the lymphatic pressure occurs secondary to congestive heart failure, constrictive pericarditis and cardiac diseases including Fontan operation. Stasis or increased pressure in the lymphatics leads to rupture in the lacteals and loss of the lymphatic fluid by the gastrointestinal system. Secondary intestinal lymphangiectasis may occur in relation with some syndromes (Table 1) $(1,2,3)$.

Fontan operation is performed in patients with functional single ventricle in whom biventricular repair is not possible and is based on conduction of the systemic venous blood directly to the pulmonary circulation $(13,14)$. In $3-15 \%$ of the patients in whom Fontan operation is performed, PLE develops approximately 2-3 years later $(14,15)$. In a multicenter study in

\section{Table 1. Causes of protein losing enteropathy}

Inflammatory and ulcerative gastrointestinal diseases

- Inflammatory bowel diseases

Crohn disese

Ulcerative colitis

- Infections

Parasitic: Giardiya lamblia

Virus: Rotavirus

Bacterial: Salmonella, Shigella, Camplobacter, Clostridium

difficile, Helicobacter pylori

Pseudomembraneous enterocolitis

- GIS malignencies

Esophagus, stomach and colon adenocarcinomas

Lymphoma

Kaposi sarcoma

- Nonsteroid antiinflammatory drug enteropathy

- Graft versus host disease

- Necrotizing enterocolitis

- Ulcerative ileitis

Non-ulcerative GIS diseases

- Hypertrophic gastropathies (Menetrier disease)

- Celiac disease

- Eosinophilis gastroenteritis

- Allergic gastroenteritis

- Tropical sprue

- Bacterial excessive growht

- Vasculitic diseases: Systemic lupus erythematosus, Henoch

Schönlein purpura

- Congenital glicolysation disorder

- Congenital enterocyte heparan sulphate deficiency

- Common variable immune deficiency

Loss from the intestinal lymphatics

- Primary intestinal lymphangiectasia

- Secondary intestinal lymphangiectasia

Cardiac diseases: Congesitve heart failure, constrictive pericarditis, cardiomyopathy, Following Fontan operation Obstruction in the lymphatics: Malrotation, lymphoma, tuberculosis, sarcoidosis, retroperitoneal fibrosis, Crohn disease, radiotherapy, chemotherapy, arsenic intoxication, portal hypertensive gastropathy, hepatic venous flow obstruction

Syndromes: Turner, Noonan, Hennekam, KlippelTrenaunay, Von Recklinghausen syndrome 
which more than 3000 patients who had undergone Fontan operation were evaluated, PLE was found to have developed in $3.7 \%$ of the patients (16). The mortality rate of PLE which develops after Fontan operation is high; $30 \%$ of the patients die in the second year after the diagnosis and $59 \%$ die in the 5 th year (14).

Although the pathophysiology of PLE which develops after Fontan operation is not clear, increase in the systemic venous pressure and right atrial pressure lead to an increase in the inferior vena cava and portal vein. This causes intestinal congestion, lymphatic stasis and enteric protein loss (14). Additionally, low cardiac output and increased mesenteric vascular resistance cause ischemia. As a result of ischemia the levels of inflammatory cytokines including TNF $\alpha$ increase. As a result of these factors the integrity of the intestinal mucosa is disrupted and protein loss into the lumen occurs. However, it is not known why PLE develops only in $3-15 \%$ of the patients who have undergone Fontane operation $(14,17,18,19)$.

Intestinal epithelium prevents the pathogenic microorganisms and products from entering into the body and inhibits loss of the plasma elements into the lumen. Proteoglycans (HSPG) including heparan sulphate and "syndecan-1" which are elements of the enterocyte basal membrane regulate cellular permeability. Decrease in HSPG or lack of HSPG in the basal membrane results in protein loss from the intestines into the lumen $(20,21)$. Murch et al. (22) found congenital intestinal heparan sulphate deficinecy in a patient who presented with diarrhea, nutritional disorder and excessive albumin loss from the intestines. In tissue culture and mouse models, it has been shown that increased venous pressure, increase in inflammatory cytokines including INF $\alpha$ and TNF $\alpha$ and loss of HSPG in the basal membrane cause protein loss from the intestines separately. The association of these three factors increases intestinal protein loss by 20 -fold by synergistic effect. Additionally, disorders of the genes which are responsible of synthesis, transfer or destruction of HSPG may cause to a predisposition to PLE. This genetic predisposition has been shown in patients with congenital glycolysation defect $1 \mathrm{~b}$ and $1 \mathrm{c}$. In these patient, genetically inadequate N-glycolysation leads to HSPG dysfunction $(5,20)$. This genetic disorder causes to a predisposition to PLE and environmental factors including intervening viral infections or inflammation cause to onset of PLE $(5,23)$.

\section{Clinical Findings}

Although the clinical findings in protein-losing enteropathy show variance depending on the underlying disease, hypoalbuminemia due to albumin loss is generally responsible of the main clinical picture. Decreased plasma oncotic pressure due to hypoalbuminemia leads to development of edema, ascites, pleural and pericardial effusion in the patients. Other ethiological factors should be considered in the differential diagnosis of hypoalbuminemia (Table 2) $(1,2)$.

In protein-losing enteropathy, other proteins are also lost from the intestines in addition to albumin. Laboratory tests may reveal decrease in albumin, gammaglobulins, fibrinogen, seruloplasmin, iron and trace elements. In PLE which develops due to lymphangiectasia, lymphopenia related to lymphocyte loss develops. This leads to secondary immune deficiency and frequent infections in the patients. In addition, defect in the absorption of fat soluble vitamins may be added to the picture. Although loss of anticoagulant proteins including protein $\mathrm{C}$ and protein $S$ also occurs, thromboembolic events are not observed frequently $(2,4)$. Conclusively, protein loss, lipid absorption disorder and vitamin-mineral loss lead to chronic nutritional disorder and somatic growth failure $(14,19)$.

\section{Diagnosis}

The diagnosis of protein-losing enteropathy is considered with history, physical examination findings and clinical findings. The definite diagnosis is made by showing increased alpha-1 antityripsin ( $\alpha 1-A T)$ excretion in the stool. Alpha-1 antityripsin is a protease inhibitor which is synthesized in the liver with a size similar to albumin (50 kdalton). Since it is not broken down in the gastrointestinal system and not absorbed from the intestines, it is a reliable indicator of intestinal protein loss (3).

Alpha-1 AT clearance is calculated with the following formula: Alpha-1 AT clearance = stool alpha-1 AT level X (24hour stool volume/serum alpha-1 AT level) (24). A clearance above $24-27 \mathrm{~mL} / 24 \mathrm{~h}$ is abnormal $(1,2)$. Alpha-1 AT excretion increases during diarrhea and GIS hemorrhage, but does not exceed $56 \mathrm{~mL}$ (2). Increased alpha-1 AT level in the stool sample is valuable in the diagnosis (3). Normally, excretion of alpha-1 AT in the stool is lower than $2.6 \mathrm{mg} / \mathrm{g}$ stool and this corresponds to a clearance of $13 \mathrm{~mL} /$ day. Therefore, clearance is more reliable, though it is troublesome. Since alpha-1 antityripsin is broken down at a $\mathrm{pH}$ below 3.5 , it may not be

\section{Table 2. Causes of hypoalbuminemia}

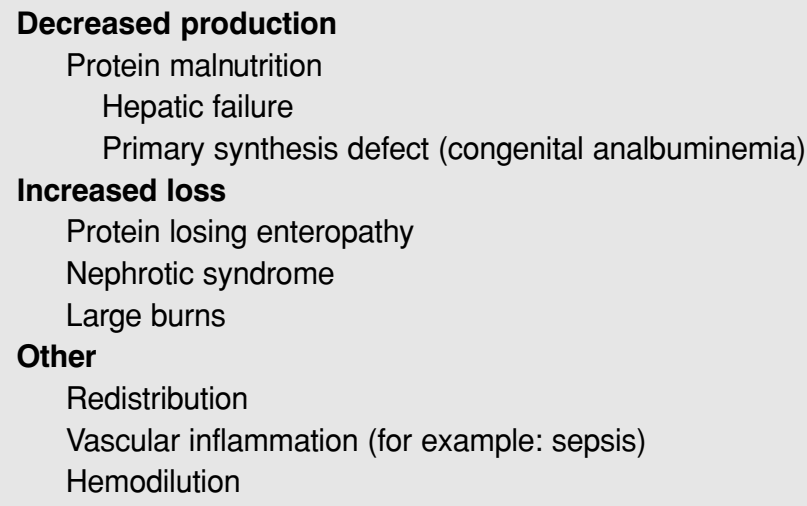


found to be high in stomach-related PLE. This may be overcome with acid supression treatment (2).

The presence of protein loss into the intestines can be demonstrated by nuclear medicine methods including human albumin labeled with Tc-99, dextran and metylene diphosphate (11). After the diagnosis of protein-losing eneteropathy is made, the ethiological factors are investigated.

In intestinal lymphangiectasias, a white velvet appearance due to enlarged lacteals on the intestinal mucosa and point

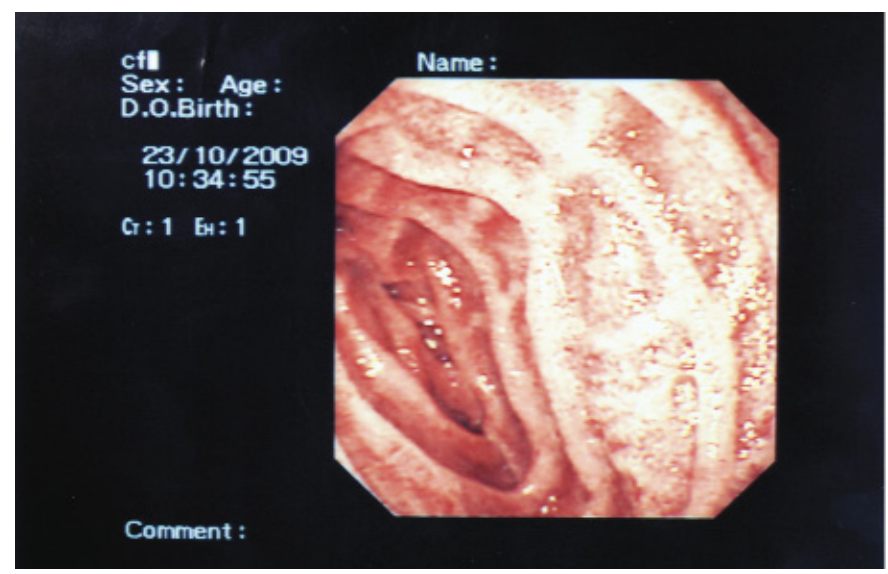

Picture 1. White velvet appearance in the duodenum on endoscopy white areas form place to place are observed on endoscopy (Picture 1). On biopsy, enlarged and distorted lacteals are observed. Endoscopic and biopsy findings may be normal in case of local and segmental involvement. In this case, the segment with lymphangiectasia may be found using video capsule endoscopy (25). Enlarged and marked intestinal and mesenteric lymphatics may be also evaluated using computerized tomography (CT) and magnetic resonance imaging (MR) $(1,11)$. The diagnostic algorithm of the disease is summarized in Figure 1.

\section{Treatment}

The treatment is based on treatment of the underlying disease and adjustment of the nutritional status of the patients. High-protein diet (1.5-3 g/kg/day) and fat-soluble and watersoluble vitamin supplements are given to the patients. For hypoalbuminemia intravenous human albumin may be needed (4). Additionally, diets poor in long chain fatty acids and rich in middle chain fatty acids are recommended. With middle chain fatty acids which enter the portal system directly without using the lymphatics the lymphatic flow and pressure are decreased and the risk of rupture of the enlarged lymphatics is reduced

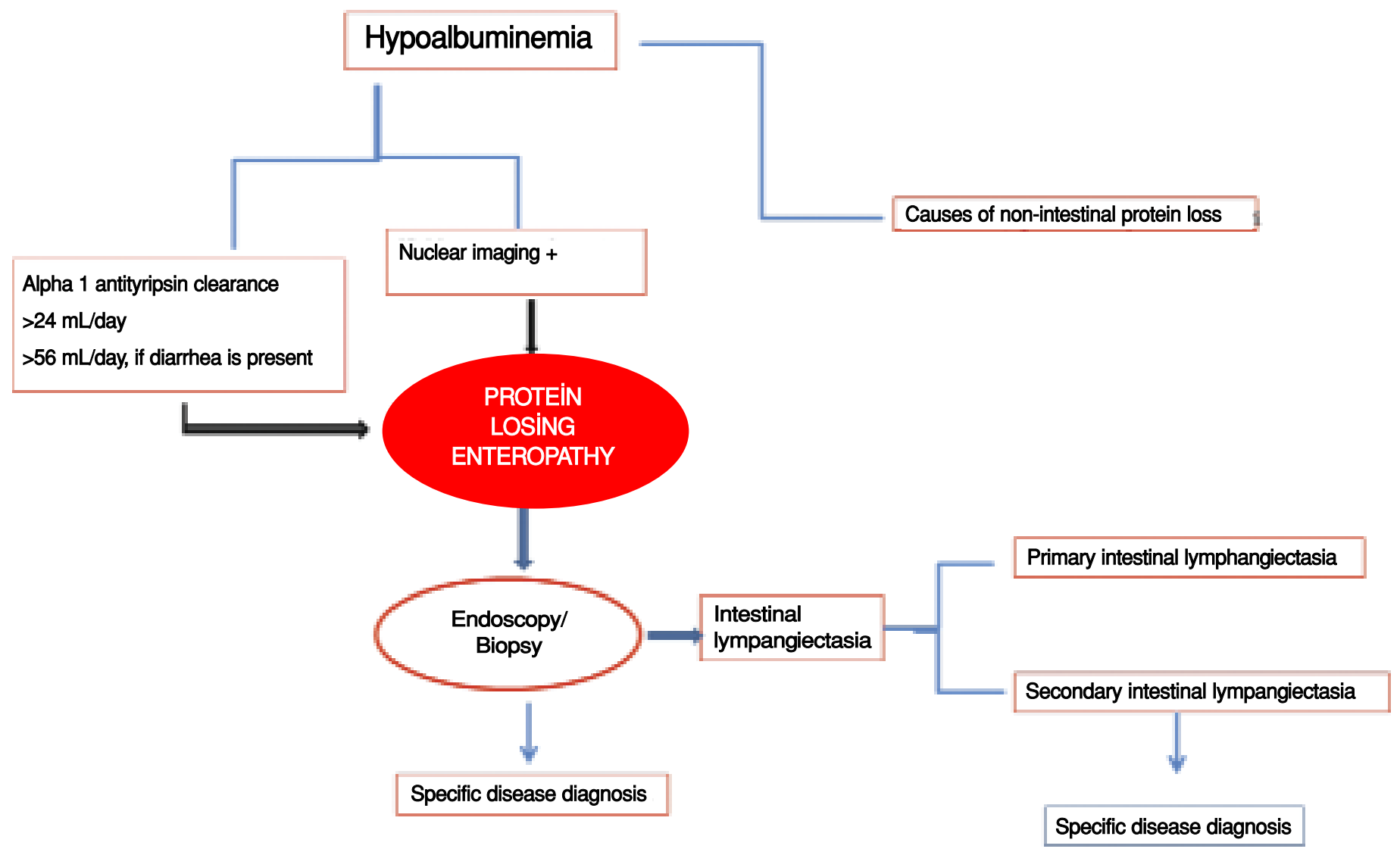

Figure 1. Diagnostic steps in protein losing enteropathy 
$(11,14)$. In treatment of primary intestinal lymphangiectasis, octreotide (150-200 microgram, 2 doses a day) can be used $(4,11)$. Although its mechanism of action is not known clearly, it is thought to prevent the lymphatic flow by reducing the splenic blood flow and to inhibit triglyceride absorption (11).

The patients should be closely monitored in terms of secondary immune deficiency because of loss of immunoglobulins and lymphocytes from the intestines and it should be ensured that all vaccines have been administered.

PLE which develops on the background of autoimmune and inflammatory diseases (allergic gastroenteritis, eosinophilic gastroenteritis, sarcoidosis, systemic lupus erythematosus, inflammatory bowel diseases, graft versus host disease etc.) benefit from steroid and immunosupressive treatment (1). PLE which develops after Fontan operation has a poor prognosis; the mortality rate after the diagnosis has been reported to be $30 \%$ for the first 2 years and $50 \%$ for the first 5 years in some studies (14). In treatment, aldosteron receptor antagonists may be used in addition to supportive treatment. High dose spiranolactone treatment decreases intestinal protein loss both with its intravascular volume and pressure reducing effect and direct mineralocorticoid receptor inhibitor effect in the renal and intestinal epithelial cells $(14,26)$. In addition, many patients have been reported to have entered remission with steroid treatment $(27,28,29)$. Intestinal lymphangiectasia has been shown to decrease on biopsies performed after steroid treatment. Steroids leads to stabilization in the intestinal capillary and lyphatic cell membranes and inhibit inflammation. Thus, they reduce protein loss. Steroid treatment is initiated with a dose of $2 \mathrm{mg} / \mathrm{kg} /$ day in children. However, it has been reported that symptoms recur when treatment is discontinued $(27,28,29)$.

In many case reports, high molecular weight heparin treatment has been shown to decrease protein loss developing after Fontan operation $(30,31,32)$. Protein loss-reducing effect of heparin is independent of its anticoagulant effect. Studies showed that heparin compensated the HSPG loss which constitutes the basis of PLE and in addition inhibited both IFN gamma and TNF alpha by binding to them. If heparin is given immediately after PLE starts, it can break the vicious circle between HSPG and the cytokines. High molecular weight heparin is recommended at a dose of $5000 \mathrm{U} / \mathrm{m}^{2} /$ day to be administered subcutaneously $(13,32)$. In a cohort study, heparin treatment was shown to provide clinical and laboratory improvement in $13(76 \%)$ of 17 patients, but remission developed only in $3(18 \%)$ patients (30). Long-term heparin treatment has severe side effects including bleeding, thrombocytopenia and osteoporosis. Therefore, an alternative treatment is needed. In the study performed by Bode et al. (5), 2.3 de-O-sulphated heparin which is a heparin derivative with no anticoagulant property decreased protein loss especially caused by cytokines in animal models.

Treatment with surgical resection may be provided in some selected cases including Menetrier disease, inflammatory bowel disease, malignencies and lymphangiectasies in certain regions which has not improved with medical treatment.

Although little is known about the prognosis of the disease, the most important indicator is the underlying disease. The mortality rate is high in the ones developing after Fontan operation $(1,11)$.

Conclusively, PLE is a clinical condition which involves different diseases in the background and which is characterized by unselective loss of proteins, vitamins and trace elements in the intestines. Hypoalbuminemia which develops as a result of loss of albumin constitutes the basis of the clinical findings in the patients. The diagnosis is made with clinical findings, increased alpha-1 antityripsin in the stool and nuclear medicine methods. Treatment and prognosis are closely related with the underlying disease. Full elucidation of the pathophysiology of the disease will enlighten new treatments.

\section{References}

1. Braamskamp MJ, Dolman KM, Tabbers MM. Clinical practice. Proteinlosing enteropathy in children. Eur J Pediatr 2010; 169: 1179-1185.

2. Umar SB, DiBaise JK. Protein-losing enteropathy: case illustraions and clinical review. Am J Gastroenterol 2010; 105(1): 43-49.

3. Proujansky R. Protein- losing enteropathy. In: Walker WA, Goulet OJ, Kleinman RE, Sanderson IR, Sherman PM, Shneider BL, (eds). Pediatric gastrointestinal disease. Ontario: BC Decker Inc, 2004: 194-202.

4. Greenwald D. Protein-losing gastroenteropathy. In: Feldman M, Friedman LS, Brandt LJ, Sleisinger MH, (eds). Gastrointestinal and liver disease. Philadelphia: Saunders, 2006: 557-563

5. Bode L, Murch S, Freeze HH. Heparan sulfate plays a central role in a dynamic in vitro model of protein-losing enteropathy. J Biol Chem 2006; 281(12): 7809-7815.

6. Iwama I, Kagimoto S, Takano T, Sekijima T, Kishimoto H, Oba A. Case of pediatric Ménétrier disease with cytomegalovirus and Helicobacter pylori co-infection. Pediatr Int 2010; 52(4): e200-203.

7. Chehade M, Magid MS, Mofidi S, Nowak-Wegrzyn A, Sampson HA, Sicherer SH. Allergic eosinophilic gastroenteritis with protein-losing enteropathy: intestinal pathology, clinical course, and long-term followup. J Pediatr Gastroenterol Nutr 2006; 42(5): 516-521.

8. Yazici Y, Erkan D, Levine DM, Parker TS, Lockshin MD. Protein-losing enteropathy in systemic lupus erythematosus: report of a severe, persistent case and review of pathophysiology . Lupus 2002; 11(2): 119-123.

9. Waldmann TA, Steinfeld JL, Dutcher TF, Davidson JD, Gordon RS Jr. The role of the gastrointestinal system in "idiopathic hypoproteinemia". Gastroenterology 1961; 41: 197-207.

10. Hokari R, Kitagawa N, Watanabe C, Komoto S, Kurihara C, Okada Y, Kawaguchi A, Nagao S, Hibi T, Miura S. Changes in regulatory molecules for lymphangiogenesis in intestinal lymphangiectasia with enteric protein loss. J Gastroenterol Hepatol 2008; 23: e88-95.

11. Vignes S, Bellanger J. Primary intestinal lymphangiectasia (Waldmann's disease). Orphanet J Rare Dis 2008; 22: 3-5.

12. Suresh N, Ganesh R, Sankar J, Sathiyasekaran M. Primary intestinal lymphangiectasia. Indian Pediatr 2009; 46(10): 903-906.

13. Lin WS, Hwang MS, Chung HT, Chu JJ, Lai MW, Yang JS, Huang SC, Huang JL, Su WJ. Protein-losing enteropathy after the Fontan operation: clinical analysis of nine cases. Chang Gung Med J 2006; 29(5): 505-512.

14. Ghanayem NS, Berger S, Tweddell JS. Medical management of the failing Fontan. Pediatr Cardiol 2007; 28(6): 465-471.

15. Mertens L, Hagler DJ, Sauer U, Somerville J, Gewillig M. Protein-losing enteropathy after the Fontan operation: an international multicenter study. PLE study group. J Thorac Cardiovasc Surg 1998; 115(5): 1063-1073. 
16. Driscoll DJ, Offord KP, Feldt RH, Schaff HV, Puga FJ, Danielson GK. Five- to fifteen year follow-up after Fontan operations. Circulation 1992; 85(2): 469-496.

17. Rychik J, Gui-Yang S. Relation of mesenteric vascular resistance after Fontan operation and protein-losing enteropathy. Am J Cardiol 2002; 90: 672-674.

18. Ostrow AM, Freeze $\mathrm{H}$, Rychik J. Protein-losing enteropathy after Fontan operation: investigations into possible pathophysiologic mechanisms. Ann Thorac Surg 2006; 82(2): 695-700.

19. Stiller B. Protein-losing enteropathy in patients with Fontan operations. J Pediatr Gastroenterol Nutr 2003; 37(5): 528-530.

20. Liem YS, Bode L, Freeze HH, Leebeek FW, Zandbergen AA, Paul Wilson $\mathrm{J}$. Using heparin therapy to reverse protein-losing enteropathy in a patient with CDG-lb. Nat Clin Pract Gastroenterol Hepatol 2008; 5(4): 220-224.

21. Westphal V, Murch S, Kim S, Srikrishna G, Winchester B, Day R, Freeze $\mathrm{HH}$. Reduced heparan sulfate accumulation in enterocytes contributes to protein-losing enteropathy in a congenital disorder of glycosylation. Am J Pathol 2000; 157(6): 1917-1925.

22. Murch SH, Winyard PJ, Koletzko S, Wehner B, Cheema HA, Risdon RA, Phillips AD, Meadows N, Klein NJ, Walker-Smith JA. Congenital enterocyte heparan sulphate deficiency with massive albumin loss, secretory diarrhoea, and malnutrition. Lancet 1996; 347: 1299-1301.

23. Bode L, Salvestrini C, Park PW, Li JP, Esko JD, Yamaguchi Y, Murch S, Freeze $\mathrm{HH}$. Heparan sulfate and syndecan-1 are essential in maintaining murine and human intestinal epithelial barrier function. $J$ Clin Invest 2008; 118(1): 229-238.
24. Akbal E, Filik L. Protein kaybettiren enteropatiler. Güncel Gastroenteroloji 2010; 14: 84-89.

25. Rivet C, Lapalus MG, Dumortier J, Le Gall C, Budin C, Bouvier R, Ponchon T, Lachaux A. Use of capsule endoscopy in children with primary intestinal lymphangiectasia. Gastrointest Endosc 2006, 64(4): 649-650.

26. Ringel RE, Peddy SB. Effect of high-dose spironolactone on proteinlosing enteropathy in patients with Fontan palliation of complex congenital heart disease. Am J Cardiol 2003; 91(8): 1031-1032.

27. Schumacher KR, Cools M, Goldstein BH, loffe-Dahan V, King K, Gaffney D, Russell MW. Oral budesonide treatment for protein-losing enteropathy in Fontan-palliated patients. Pediatr Cardiol 2011; 32(7): 966-971.

28. Thacker D, Patel A, Dodds K, Goldberg DJ, Semeao E, Rychik J. Use of oral budesonide in the management of protein-losing enteropathy after the Fontan operation. Ann Thorac Surg 2010; 89(3): 837-482.

29. Hoashi T, Ichikawa H, Ueno T, Kogaki S, Sawa Y. Steroid pulse therapy for protein-losing enteropathy after the Fontan operation. Congenit Heart Dis 2009; 4(4): 284-287.

30. Ryerson L, Goldberg C, Rosenthal A, Armstrong A. Usefulness of heparin therapy in protein-losing enteropathy associated with single ventricle palliation. Am J Cardiol 2008; 101(2): 248-251.

31. Bendayán I, Casaldaliga J, Castelló F, Miró L. Heparin therapy and reversal of protein-losing enteropathy in a case with congenital heart disease. Pediatr Cardiol 2000; 21(3): 267-268.

32. Donnelly JP, Rosenthal A, Castle VP, Holmes RD. Reversal of protein-losing enteropathy with heparin therapy in three patients with univentricular hearts and Fontan palliation. J Pediatr 1997; 130(3): 474-478. 